\title{
Telomere dynamics in the Sydney rock oyster (Saccostrea glomerata): an investigation into the effects of age, tissue type, location and time of sampling
}

\author{
Rosamond Godwin - Ian Brown - Steven Montgomery • \\ Stewart Frusher $\cdot$ Timothy Green $\cdot$ Jennifer Ovenden
}

Received: 31 August 2010/Accepted: 29 August 2011/Published online: 16 September 2011

(C) Her Majesty the Queen in Rights of Australia 2011

\begin{abstract}
Telomere length has been purported as a biomarker for age and could offer a non-lethal method for determining the age of wild-caught individuals. Molluscs, including oysters and abalone, are the basis of important fisheries globally and have been problematic to accurately age. To determine whether telomere length could provide an alternative means of ageing molluscs, we evaluated the relationship between telomere length and age using the commercially important Sydney rock oyster (Saccostrea glomerata). Telomere lengths were estimated from tissues of known age individuals from different age classes,
\end{abstract}

Communicated by R. H. Richmond.

R. Godwin $(\bowtie) \cdot$ J. Ovenden

Molecular Fisheries Laboratory, Agri-Science Queensland,

Department of Employment, Economic Development and Innovation, The University of Queensland,

Level 3 Ritchie Building (64A C-Wing), Research Road,

Brisbane 4067, Australia

e-mail: Rosamond.Godwin@deedi.qld.gov.au

I. Brown

Sustainable Fisheries Programme, Agri-Science Queensland, Department of Employment, Economic Development and Innovation, Southern Fisheries Centre, 13 Beach Rd, PO Box 76, Deception Bay, QLD 4508, Australia

\section{S. Montgomery}

Industry and Investment NSW, Cronulla Fisheries

Research Centre of Excellence, PO Box 21,

Cronulla, NSW 2230, Australia

S. Frusher

Tasmanian Aquaculture and Fisheries Institute,

University of Tasmania, Private Bag 49, Hobart 7001, Australia

T. Green

School of Biological Sciences, The University of Queensland, St Lucia, QLD 4072, Australia locations and at different sampling times. Telomere length tended to decrease with age only in young oysters less than 18 months old, but no decrease was observed in older oysters aged 2-4 years. Regional and temporal differences in telomere attrition rates were also observed. The relationship between telomere length and age was weak, however, with individuals of identical age varying significantly in their telomere length making it an imprecise age biomarker in oysters.

\section{Introduction}

Information about the ages of individuals is needed to estimate the age structure of a population. This gives insights into the growth rates, mortality and productivity of the population and so is an integral component of sustainable fisheries management. Techniques for collecting information about the ages of fish resources have been well documented and extensively evaluated but are still susceptible to errors (Campana 2001). Inaccurate age estimations when applied to fisheries management can have serious consequences leading to overexploitation or a collapse of populations or species as exemplified by Campana (2001).

Age and growth information of mollusc species has also been problematic with a range of techniques applied including tag-recapture methods (McShane et al. 1988), counting growth rings of shells, studying the ratio of isotopes in the carbonate of shells (Keller et al. 2002; Gurney et al. 2005; Naylor et al. 2007; Goewert and Surge 2008) and cohort or length frequency analyses (Shepherd et al. 1995; Tarr 1995; Siddeek and Johnson 1997). Although these methods have provided useful information, they tend to be species specific, time-consuming and labour 
intensive, require careful validation and are often deleterious or lethal to the organism. The development of a DNA-based method for estimating the age of shellfish may provide an alternative to traditional methods and could be more direct, less expensive and quicker and could be performed non-lethally.

Telomeres are ribonucleoprotein structures at the ends of linear chromosomes composed of short, tandem, highly repeated DNA sequences and associated proteins. Their main function is to protect the ends of the chromosomes from degradation and hence to provide genome stability (Szostak and Blackburn 1982; Blackburn 1991). Haussmann and Vleck (2002) and others (Tsuji et al. 2002; Haussmann et al. 2003; Vleck et al. 2003) suggested that the telomeric DNA at the ends of chromosomes could provide an additional tool for ageing animals since telomeric DNA of somatic cells normally shortens with progressive cell divisions over an animal's lifespan due to the 'end-replication problem' (Watson 1972). A significant correlation has been observed between age and telomere length for humans (von Zglinicki and Martin-Ruiz 2005), some species of birds (Haussmann and Vleck 2002; Haussmann et al. 2003; Vleck et al. 2003; Nakagawa et al. 2004) and fish (Ying 2005; Hatakeyama et al. 2008; Hartmann et al. 2009). Despite this, more recent evidence amongst ecologists suggests that telomere length will have limited application as an age biomarker because there is significant variation in telomere length amongst individuals of the same age and because many endogenous and exogenous factors affect telomere dynamics (Horn et al. 2010; Monaghan 2010; Dunshea et al. 2011).

In this study, the terminal restriction fragment (TRF assay) was used to determine whether a relationship between telomere length and age exists in oysters. This robust method is appropriate for species with limited genome resources available, to estimate telomere length from individuals when the amounts of available tissue are not limiting. However, if a strong relationship is detected, it would be desirable to develop a high throughput, quantitative PCR method that would allow non-lethal sampling from very small tissue samples such as biopsies of skin or muscle or from haemolymph. This sample could also be used for genetic stock identification and gender assays.

The telomere repeat sequence TTAGGG has been described for a number of bivalve molluscs such as Pacific oyster (Crassostrea gigas) (Guo and Allen 1997), bay scallop (Argopecten irradians), blue mussel (Mytilus galloprovincialis), wedgeshell clam (Donax trunculus) (Plohl et al. 2002) and sand scallop (Euvola ziczac) (Owen et al. 2007). Telomerase is an important enzyme that counteracts telomere attrition (Greider and Blackburn 1985, 1989). It has been found to be active in all tissues of lobsters
(Klapper et al. 1998b), sea urchins (Francis et al. 2006) and some bivalves (Owen et al. 2007), and it has been suggested that sustained telomerase activity is necessary, in species with indeterminate growth or high regenerative potential, to maintain telomeres throughout their lifespan (Klapper et al. 1998a, b). In animals exhibiting continuous telomerase expression, or other maintenance mechanisms throughout their tissues, it is possible that little association exists between telomere length and age.

The Sydney rock oyster (Saccostrea glomerata) (formerly $S$. commercialis) is a highly valuable seafood resource in Australia. It is endemic from $19^{\circ} \mathrm{S}$ to $37^{\circ} \mathrm{S}$ on the Australian east coast (Nell 2001; O'Connor and Dove 2009) but also occurs on Australia's north and western coastlines and is also endemic in New Zealand. Oyster farming occurs along the east coast of Australia in the mid to lower intertidal zone of marine estuaries and bays.

Sarccostrea glomerata was selected as a model species to test for a relationship between telomere length and age in a mollusc species because of its distribution over a wide latitudinal range and ready access to individuals of known age. We hypothesised that the relationship between telomere length and age would be significant in at least one tissue type and consistent between different environments. Additionally, we tested whether the relationship was repeatable in one environment through time. These characteristics are essential for telomere length to be a satisfactory biomarker of age.

This work is part of a larger study to determine whether telomeric analyses offer a new, cost-effective method for collecting biological information on aquatic species, particularly those that are difficult to age using conventional techniques.

\section{Methods}

Sampling of tissues

The relationship between telomere length and age in S. glomerata was examined by studying cultured oysters of known age in two different regions and by studying oysters from a single location sampled at two different times. Farmed oysters are usually marketed at three to 4 years of age; thus, older oysters of known age were unavailable for the study. The age classes studied were largely governed by availability of oysters at the time of sampling.

The study encompassed three experiments. The aim of experiment one was to assess the relationship between telomere length and age in oysters from one locationMoreton Bay, Queensland, Australia $\left(27^{\circ} 20^{\prime} \mathrm{S}, 153^{\circ} 23^{\prime} \mathrm{E}\right)$. Oysters known to be 1, 3 and 4 years old were obtained in 
2007. Telomere length estimates were made on individuals from the three age classes using gill and mantle tissue.

In experiment two, we examined the relationship between telomere length and age in another location Wallis Lake, Tuncurry, New South Wales, Australia $\left(32^{\circ} 11^{\prime} \mathrm{S}\right.$, $152^{\circ} 28^{\prime} \mathrm{E}$ ) which is approximately $700 \mathrm{~km}$ and $5^{\circ}$ of latitude south of Moreton Bay. Oysters aged 1, 3 and 4 years were obtained from a farm in 2009. One-year-old oysters were removed from their shells and sampled whole owing to their small size, but gill and mantle tissue was dissected from 3- to 4-year-old individuals. Additionally, oysters of 1.5 years of age were obtained from this location 6 months later since the availability of 1-year-old oysters was limited. Gill tissue only was used for telomere length estimates of 1.5-year-old oysters.

Experiment three assessed temporal effects on the relationship between telomere length and age at a single location, Moreton Bay. A second sampling was conducted at the Moreton Bay farm in 2009, 2 years after the first sampling. Oysters aged 2 months and 1 and 2 years were available for testing, and gill tissue only was used. This was because DNA extracted from mantle had previously been more susceptible to degradation than DNA from gill tissue and therefore additional effort was made to separate the gill tissue away from the remaining tissues even in 2-month-old oysters.

Moreton Bay oysters were derived from hatchery-produced spat, whereas Wallis Lake oysters originated from natural-caught spat. Live oysters were taken from the sea and shipped from each location to the laboratory by overnight courier. At the laboratory, live oysters were opened and their tissues dissected as outlined above. Tissue samples were placed in 2-ml cryotubes, snap frozen and then transferred immediately to $\mathrm{a}-80^{\circ} \mathrm{C}$ freezer for storage.

Extraction of total genomic DNA and terminal restriction fragment assays

The terminal restriction fragment (TRF) assay provides an estimate of mean telomere length per individual. Highmolecular weight genomic DNA was extracted from frozen tissue using the standard method of Sambrook and Russell (2001). This involved cell lysis in the presence of EDTA, sodium dodecyl sulphate (SDS) and proteinase $\mathrm{K}$ followed by phenol/chloroform extractions and ethanol precipitation. The resulting DNA was redissolved in TE (Tris-EDTA) buffer $\mathrm{pH} 8.0$ and $1 \mathrm{mM}$ DTT (dithiothreitol) to minimise degradation and oxidation of the telomeric DNA. A range of TRF assays were conducted on oysters using genomic DNA from mantle, gill or whole animal.

The TRF assays were performed using the TeloTAGGG Telomere Length Assay kit (Roche Diagnostics Australia Pty. Ltd, Castle Hill, NSW, Australia) with the following specifications and modifications. The telomere repeat sequence of $S$. glomerata was assumed to be TTAGGG as reported for other molluscs (Guo and Allen 1997; Estabrooks 1999; Plohl et al. 2002; Sakai et al. 2005), and hybridisation of the probe to oyster genomic DNA was confirmed by dot blot (data not shown).

Prior to each set of TRF assays, the quantity and integrity of genomic DNA extracts were checked by gel electrophoresis. Gel electrophoresis was used for the quantification of DNA since there was poor correlation between OD260 spectrophotometer readings and the amount appearing on a gel. It was felt that co-purification products (e.g. dyes and pigments from the oyster's tissues) interfered with OD260 readings. These products were not easily removed during the phenol/chloroform clean-up. Fluorometry was not used to quantify DNA since this equipment was not available. To the best of our knowledge, the amount used per lane was close to $2 \mu \mathrm{g}$, and considerable effort was made to ensure that loading levels were consistent across gels and lanes.

Genomic DNA was digested with HinfI and RsaI for $3 \mathrm{~h}$ at $37^{\circ} \mathrm{C}$ and separated using conventional gel electrophoresis on a $1 \times$ TAE $0.8 \%$ agarose gel at $35 \mathrm{~V}$ for $20 \mathrm{~h}$ at $4^{\circ} \mathrm{C}$. Samples were loaded in randomised order on every gel to minimise within-gel effects. Typically, six individuals were used per tissue per age class making a total of 18 samples per TRF assay. Each assay was repeated on three occasions. To provide controls, three Moreton Bay oysters were included in assays with the Wallis lake oysters.

DNA was denatured prior to transfer to nylon membrane, and subsequent transfer, hybridisation, chemiluminescence and detection were according to the Roche TeloTAGGG kit instructions. Chemiluminescent signals from the membrane were captured on X-ray film using multiple exposures as appropriate.

\section{Determination of telomere length}

Estimates of telomere length were obtained by comparing the telomere smear to a molecular size standard. X-ray films were scanned using a high-definition scanner and uploaded into Quantity One Version 4.2.3 imaging software (Biorad, Gladesville, NSW, Australia) for analysis. An example of an autoradiograph obtained from an oyster TRF assay is shown in Fig. 1. The telomere smear was visible in the top half of each lane and below each smear was a pattern of bands that appeared to vary between individuals. This banding pattern was assumed to be associated with interstitial and subtelomeric (IST) repeats.

Mean TRF measurements were determined by the method outlined in the Roche TeloTTAGG Telomere Length Assay Protocol. In summary, each lane was overlaid with a grid of 25 equal-sized boxes, which spanned the 


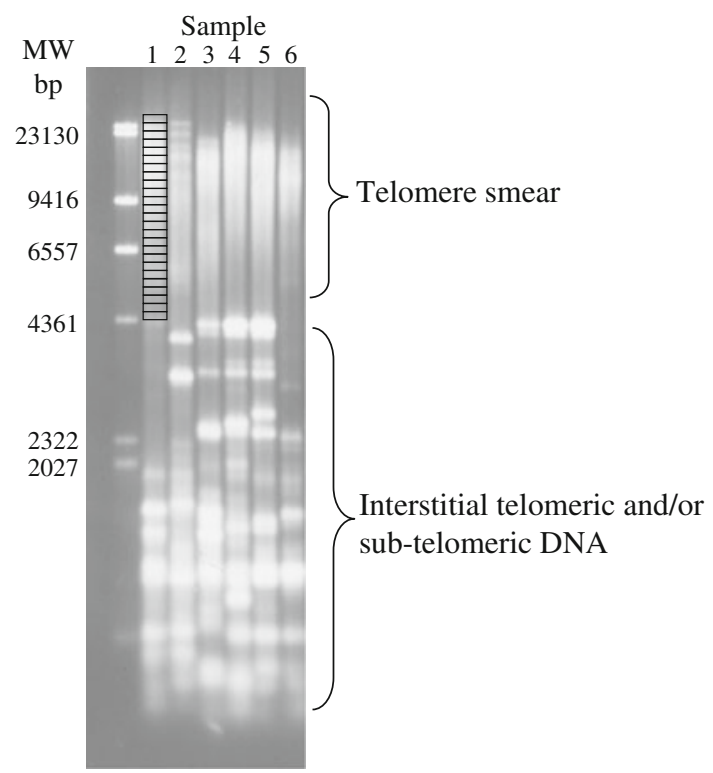

Fig. 1 Saccostrea glomerata samples from mantle DNA were assayed for mean telomere length. Telomeric DNA appears as a smear above a prominent banding pattern presumed to be derived from interstitial and subtelomeric repeated DNA. Each lane was overlaid with a grid of 25 boxes before total intensity and molecular weight were estimated for each box

lane from above the largest molecular weight marker $(23,130 \mathrm{bp})$ and excluded bands associated with the IST DNA (Fig. 1). The total intensity inside each box and molecular weight at the centre of each box were estimated using Quantity One software (Biorad). A minimum background subtraction as suggested in the Roche protocol was applied in each lane whereby the box with the lowest signal volume was subtracted from each of the remaining 24 boxes in each lane.

Telomere length for an individual oyster was calculated from the TRF assay using the formula

Mean telomere length $=\Sigma\left(\mathrm{OD}_{i}\right) / \Sigma\left(\mathrm{OD}_{i} / L_{i}\right)$

where OD is the total chemiluminescent signal in each box, and $L_{\mathrm{i}}$ is the length of the TRF fragment at the position ' $i$ '. This formula takes into account the higher signal intensity from larger TRFs due to multiple hybridisations of the telomere-specific hybridisation probe.

Estimates of between experiment coefficients of variation were made by repeating samples across at least three gels.

Data analysis

All data were subjected to analysis of variance (ANOVA) using GenStat (Payne et al. 2009). The individual oysters were taken as the independent experimental units, with split-plots adopted for the different tissues (when appropriate) and also for the replicate measurements of the same individuals. Telomere length was the dependent variable, with age groups and tissue types being the independent factors for these analyses. Inspection of residual plots indicated that no transformation of the data was necessary. Least significant difference (LSD) testing was applied when the ANOVA indicated a significant $(P<0.05)$ difference. In some cases, unpaired Student's $t$ tests were used to compare means of different age classes.

For experiment one data, obtained from 2007 oysters from Moreton Bay, the ANOVA terms were age, tissue and their interaction. Experiment two did not contain a complete data set for every age class for gill and mantle tissue. Therefore, the effect of age on telomere length was analysed separately for each tissue using a one-way design. For gill tissue, the 1.5-, 3- and 4-year-old age classes were compared, whereas for mantle tissue, only the 3- and 4-year-old age classes were compared. Telomere lengths of 1 -year-olds were estimated from whole bodies containing a mixture of tissues. Therefore, these data were not included in ANOVAs for individual tissues.

In experiment three, the effect of age on telomere length was examined in the second sampling of oysters from Moreton Bay in 2009, using a one-way design with data obtained from gill tissue.

\section{Results}

Experiment 1. The effect of age and tissue type on telomere length of Moreton Bay oysters

The average telomere length of oysters sampled from Moreton Bay in 2007 was 9,007 bp. Estimates amongst the sampled individuals varied from 5,306 to $14,541 \mathrm{bp}$.

The effect of age on telomere length for both gill and mantle tissue was just outside the $P=0.05$ level of significance (ANOVA $F_{(2,15)}=2.97, P=0.08$ ) providing reasonable evidence that a relationship between telomere length and age may exist. Unpaired $t$ tests showed that 1-year-old oysters had significantly longer telomeres, based on gill tissue, than 3 -year olds $\left(t_{10}=2.30, P=0.04\right)$; however, there was no significant difference between 1- and 4-year-old oysters. In mantle tissue, telomere lengths of 1-year-old oysters were significantly longer than both 3-year-old $\left(t_{10}=2.98, P=0.01\right)$ and 4-year-old oysters $\left(t_{10}=2.75, P=0.02\right)$. Telomere length between 3- and 4-year olds did not differ for either tissue (Table 1). The telomeres of 1-year-old oysters were approximately 2,400 bp longer than those of 3-year olds, suggesting an attrition rate of around $1,200 \mathrm{bp}$ year $^{-1}$ between 1 and 3 years of age. 
Table 1 Telomere length estimates (bp) for Saccostrea glomerata from Moreton Bay sampled in 2007 and Wallis Lake, aged 1-4 years using DNA extracted from gill and mantle tissue

\begin{tabular}{llllll}
\hline Age (years) & \multicolumn{2}{l}{ Moreton Bay } & & & Wallis Lake \\
\cline { 2 - 3 } \cline { 5 - 6 } & Gill & & Mantle & & Gill \\
\hline 1 & $10,580 \pm 1,543(6)^{\mathrm{a}}$ & $10,362 \pm 812(6)^{\mathrm{a}}$ & & - & - \\
1.5 & - & - & & $8,228 \pm 1,491(12)^{\mathrm{a}}$ & - \\
3 & $8,477 \pm 1,620(6)^{\mathrm{b}}$ & $7,783 \pm 1,961(6)^{\mathrm{b}}$ & & $7,635 \pm 1,680(6)^{\mathrm{a}}$ & $8,369 \pm 2,031(6)^{\mathrm{a}}$ \\
4 & $8,829 \pm 2,884(6)^{\mathrm{ab}}$ & $8,010 \pm 1,934(6)^{\mathrm{b}}$ & & $6,783 \pm 1,454(5)^{\mathrm{a}}$ & $7,719 \pm 1,292(6)^{\mathrm{a}}$ \\
CV\% between animals & 39 & 33 & & 35 & 36 \\
CV\% between reps & 11 & 14 & & 11 & \\
\hline
\end{tabular}

Mean values \pm standard deviation and number of individuals in parenthesis are presented. Different letters indicate significant differences $(P<0.05)$ between age group means for each tissue type within each location. Coefficient of variation expressed as a percentage $(\mathrm{CV} \%)$ between sampled animals and between replicate measurements (reps) is included

The pattern of decrease in telomere length with age was similar for each tissue type (Table 1), although telomere lengths of gill tissue were consistently longer than those of mantle tissue (ANOVA $F_{(1,15)}=4.84, P=0.04$ ). Mean telomere lengths estimated from gill and mantle tissue across all individuals in all age groups were 9,295 and $8,719 \mathrm{bp}$, respectively.

Experiment 2. The relationship between telomere length, age and tissue in a second environment

Regional differences in the relationship between telomere length and age were investigated using farmed oysters of ages 1, 3 and 4 years from Wallis Lake Tuncurry (New South Wales).

The average telomere length of oysters from Wallis Lake was 7,873 bp (approximately 13\% lower than Moreton Bay). Estimates amongst the sampled individuals varied from 4,920 to $12,995 \mathrm{bp}$.

Data from 1-year-old oysters from Wallis Lake were excluded from comparisons between age classes because tissue types were not separated. One-year-old oysters from Wallis Lake were sampled whole and therefore telomere lengths were estimated from a mixture of tissues including gill, mantle tissue, adductor muscle, digestive gland and stomach tissue. A mean telomere length of 7,785 bp was estimated for 1-year-old individuals $(n=10)$, which was approximately $2,700 \mathrm{bp}(25 \%)$ lower than that estimated from gill and mantle tissue for 1-year-old Moreton Bay oysters.

Though there was a trend for telomere length from gill tissue to decrease with age for Wallis Lake oysters, differences between the age group means were smaller than at Moreton Bay and were non-significant (ANOVA $\left.F_{2,22}=1.57, P=0.23\right)$. Telomere lengths of $3-$ and 4-year-old Wallis Lake oysters were comparable to those of similar-aged Moreton Bay oysters with age group means being in the range of approximately $6,700-8,800 \mathrm{bp}$ (Table 1). However, estimates of telomere length from 1.5-year-old oysters at Wallis Lake were over 1,500 bp lower than those from 1-year-old oysters at Moreton Bay.

The difference in telomere length between three- and four-year-old oysters from Wallis Lake based on mantle tissue was also non-significant. Telomere length estimates were only obtained from mantle tissue of 3- and 4-year-old Wallis Lake oysters and not from 1.5-year-old oysters (Table 1).

Experiment 3. Temporal effects on the relationship between telomere length and age in Moreton Bay

Telomere lengths were estimated from gill tissue of a second sample of Moreton Bay oysters collected in 2009: 2 months old and 1 and 2 years old (Table 2). Age had a significant effect on the telomere length for the three age groups sampled in 2009 (ANOVA $F_{2,25}=16.69$, $P<0.001)$, with the mean for 2-month-old oysters (8,892 bp) being greater than 1-year-old $(5,918 \mathrm{bp})$ and 2 -year-old oysters (5,672 bp). Telomere lengths of 1- and 2-year-old oysters did not differ significantly from one another (Fisher's LSD $=1,277, P=0.05$ ).

Telomere lengths for age classes from the 2007 and 2009 samples from Moreton Bay were not consistent between temporal resamplings (Fig. 2). Telomere lengths recorded for 2-month-old oysters in 2009 were similar to those recorded for the 1-year-old oysters collected in 2007. If telomere attrition rates and telomere lengths in larvae were constant between sampling events, younger oysters should have longer telomeres than older oysters. However, telomeres for the 1- and 2-year-old oysters in 2009 were on average 2,000 bp shorter than telomeres of 3- and 4-yearold oysters assayed in 2007 (Table 2). Telomere length tended to decrease across the age groups for both the 2007 and 2009 samples. In general, the telomere lengths of the 
Table 2 Comparison of telomere length estimates for Moreton Bay Saccostrea glomerata sampled in 2007 and 2009 based on DNA extracted from gill tissue

\begin{tabular}{llc}
\hline Sample group & Age (years) & Mean telomere length (bp) \\
\hline 2007 & 1 & $10,580 \pm 1,543(6)^{\mathrm{a}}$ \\
& 3 & $8,477 \pm 1,620(6)^{\mathrm{b}}$ \\
& 4 & $8,829 \pm 2,884(6)^{\mathrm{ab}}$ \\
2009 & 0.17 & $8,892 \pm 2,412(8)^{\mathrm{a}}$ \\
& 1 & $5,918 \pm 617(10)^{\mathrm{b}}$ \\
& 2 & $5,672 \pm 657(10)^{\mathrm{b}}$ \\
\hline
\end{tabular}

Mean values \pm standard deviation and number of individuals in parenthesis are presented. Different letters indicate significant differences $(P<0.05)$ between age groups within each sample year

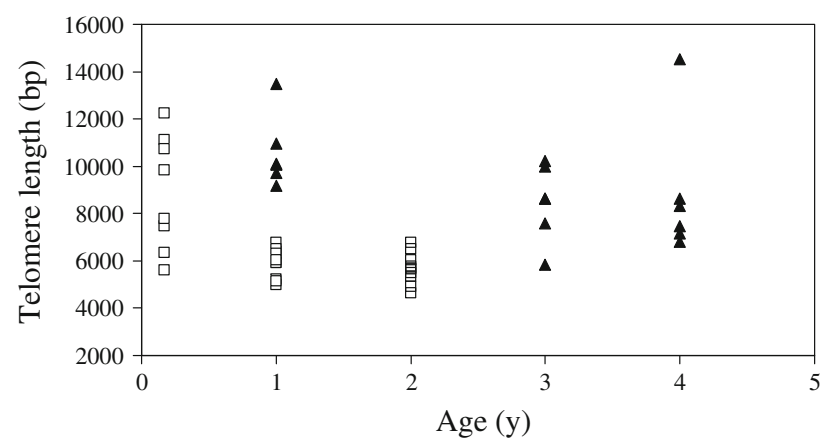

Fig. 2 The range of telomere length estimates for Saccostrea glomerata individuals in each of three age groups sampled from Moreton Bay in 2007 and 2009. Telomere lengths were based on DNA extracted from gill tissue. Closed symbols represent samples from 2007, and open symbols represent samples from 2009

2009 sample group were shorter than the 2007 group (Fig. 2).

Generally, the variability within a given age class was similar for the 2007 and 2009 samples (Fig. 2). The coefficient of variation amongst individuals in the 2007 sample population (across three age cohorts) was 39\% compared to $35 \%$ for the 2009 group. Most of the variation amongst individuals in the 2009 sample was amongst the 2-monthold oysters (Fig. 2).

\section{Assessment of the variation in estimates between replicate experiments}

Coefficients of variation between replicate experiments of oysters were between 10 and 14\%. Within-gel effects are likely to be smaller than this. Although the within-gel effects were not tested for oysters, preliminary experiments in our laboratory with a range of other mollusc and crustacean species indicated that $\mathrm{CVs}$ between repeated measurements within one experiment (i.e. for a replicate measurement of a single individual run three times on one gel) were 1-3\% (data not shown).

\section{Discussion}

Comparison of telomeres in oysters

with other mollusc species

Like other molluscs, $S$. glomerata have the telomeric repeat sequence TTAGGG; however, telomere lengths vary substantially between mollusc species. Telomere lengths of $0.75-2.3 \mathrm{~kb}$ have been reported for digestive gland tissue of bay scallops (Argopecten irradians), whilst another species in this genus (A. purpuratus) had much longer telomeres $(9.4 \mathrm{~kb})$ (Estabrooks 2007). Even longer telomere lengths $(>20 \mathrm{~kb})$ were recorded for both somatic and germline tissues of sand scallop (Euvola ziczac) (Owen et al. 2007). Our estimates of telomere length for S. glomerata (4-14 kb) fell within this general range. There are no other estimates of telomere lengths in oysters or other bivalve molluscs.

The genome of S. glomerata appears to contain significant amounts of interstitial or subtelomeric (IST) repeated sequences. Fluorescence in situ hybridisation (FISH) or Bal31 assay could provide confirmation of this. Interstitial telomeric DNA has also been detected using the TRF assay in the genome of bay scallops (A. irradians) (Estabrooks 2007) but not in the Pacific oyster (Crassostrea gigas) (Guo and Allen 1997) or Portuguese oyster (C. angulata) (Cross et al. 2005). The IST bands observed in oysters vary between individuals. Some of these bands were close to the bottom of the telomere smear, and inclusion of these bright, lower-molecular weight bands in estimates of telomere length has the effect of skewing mean estimates downwards. Therefore, when estimating and reporting telomere length in species with IST bands, it is essential to stipulate the molecular weight range of fragments that are included in telomere length estimates.

The relationship of telomere length with age in $S$. glomerata

Though there was a tendency for telomere length to decrease with age in the groups of $S$. glomerata sampled in this study, this was only significant at Moreton Bay. At Moreton Bay, the decrease was irrespective of tissue or time of sampling and occurred over the younger portion of the lifespan of the species. The greatest attrition in telomeres occurred when oysters were under the age of 1.5 years which coincides with the oyster's greatest period of growth, differentiation and sexual maturation (Dinamani 1974). After this time, telomere length appeared to remain constant. Individuals in this study ranged in age from 2 months to 4 years old, which may represent only about a third of the species' lifespan. Whilst there is no definitive 
information on the lifespan of $S$. glomerata in the wild, they are thought to live from 6 to 10 years.

We expected that telomere length would decline with age because of the 'end-replication problem', but other cellular processes associated with ageing can also contribute to telomere attrition. Common features of the ageing process in bivalve species involve a loss of energetic function and higher susceptibility to stress (Philipp and Abele 2010) and a decline in antioxidant defence and protective chaperones (Ivanina et al. 2008). Telomere shortening has been reported to happen irrespective of telomerase activity due to reactive oxygen species (ROS)related damage (Passos et al. 2007). In bivalves, periods of shell closure can result in hypoxic or even anoxic conditions for internal tissues which may in turn affect the expression of genes in a variety of physiological pathways and in particular levels of reactive oxygen species (ROS) in their tissues (David et al. 2005). Though oysters in this study were only used if their shells were closed, we do not have precise information for each cohort on how long the shells were closed between leaving the water and experimentation. The maximum amount of time was thought be $72 \mathrm{~h}$. Variations in this length of time may therefore have only made a minor, if any contribution to the observed heterogeneity in telomere lengths.

There have been few studies on telomere dynamics with age in other mollusc species, although telomere length was reported to have decreased with age in digestive gland but not heart or adductor muscle of bay scallop A. irradians (Estabrooks 2007). This preliminary study had low replication, and as we have found digestive gland DNA is highly susceptible to degradation, this could explain some of the shortening observed by Estabrooks (2007).

The measureable decrease in telomere length with age in $S$. glomerata suggests that telomere maintenance mechanisms, which may be active in adult somatic cells of oysters, may not be sufficient to maintain telomere length over the oyster's 10-year lifespan. In some marine invertebrates such as jellyfish (Cassiopea andromeda) (Ojimi and Hidaka 2010), sea urchins (Lytechinus variegates and Strongylocentrotus franciscanus) (Francis et al. 2006), lobsters (Homarus americanus) (Klapper et al. 1998b) and sand scallop (Euvola ziczac) (Owen et al. 2007), ubiquitous telomerase expression has been found to occur in adult somatic and germline tissues, and this may provide a mechanism to maintain telomeres (Owen et al. 2007). Telomerase activity in S. glomerata was not assayed in this study; however, in future research, this would be possible using a procedure such as the telomere repeat amplification protocol (TRAP) assay (Kim et al. 1994).
Relationship between telomere length and tissue type

Telomere length tended to be shorter in mantle tissue than in gill tissue particularly in the 3- and 4-year age classes of Moreton Bay oysters. At Wallis Lake, however, telomere lengths appeared to be longer in mantle than gill although this difference was not significant. This was most likely due to the variability between individual oysters within the sample groups and also because telomere length of mantle was only tested across the three- and four-year age groups. A larger sample group across a wide age range would be necessary to detect any measurable difference in telomere length.

The decrease in telomere length with age was consistent for mantle and gill tissue. This was contrary to our expectation that the telomere rate of change with age would be higher in gill tissue than in mantle, since the metabolic activity and cell turnover rates associated with maintaining ciliary epithelia in gills would be expected to be greater than that of mantle tissue (Philipp and Abele 2010). We therefore conclude that the cell turnover rates in the two tissue types are likely to be equal or there is a mechanism of telomere maintenance in gill tissue to compensate for faster cell turnover rates.

Regional effects on the relationship between telomere length and age

Environment may exert a significant effect on the relationship between telomere length and age. It may affect both absolute telomere length and the rate at which it decreases with age. Telomere lengths tended to be shorter in oysters from Wallis Lake than those at Moreton Bay, and whilst there was a significant relationship between age and telomere length at Moreton Bay, the relationship between age and telomere length at Wallis Lake was not significant. Sampling a larger number of oysters over wider age range (up to 10 years) would be needed to assess whether the decrease in telomere length continued over the entire lifespan.

The observed differences between locations could be genetically based since Moreton Bay oysters were derived from commercially produced spat that were part of a breeding programme, whereas Wallis Lake oysters were derived from wild-caught spat. Hatchery-produced selectively bred spat have been found to grow faster in terms of shell size and whole weight than wild-caught spat (Dove and O'Connor 2009), and it is possible that the two groups also vary in their telomere dynamics over their life cycle.

The disparity between results obtained from Moreton Bay and Wallis Lake oysters may also be a reflection of the different environments in which the oysters have been reared. The location of the Moreton Bay farm is a completely marine environment $20 \mathrm{~km}$ from the coast adjacent 
to the large sand island (Moreton Island). Thus, the area is less subject to the seasonal effects of freshwater runoff that might affect nutrient levels, salinity and turbidity levels of the estuarine environment at Wallis Lake. The two regions have different seasonal water temperatures since Moreton Bay is around $700 \mathrm{~km}$ north of Wallis Lake on Australia's eastern seaboard. Whilst information regarding environmental effects on ageing of bivalves is limited, studies in other organisms have indicated that the rate of telomere loss was sensitive to cell division rates and environmental circumstances in the cell (Jennings et al. 2000; von Zglinicki 2002).

Temporal effects on telomere length

Our results showed that overall mean telomere lengths of similar-aged oysters from a given location can differ by at least 2,000 bp in a 2-year interval between sampling times. Validation experiments excluded the possibility that this was due to measurement error. Telomere length decreased with age in 2007 and 2009 sample groups. The decrease in telomere length appeared to occur at a younger age for the 2009 group; however, we cannot make this assumption since oysters less than a year old were unavailable in the 2007 group.

Telomere lengths of identically aged oysters, in the 1- and 2-year age classes, were far more uniform in 2009 than any other age groups from Moreton Bay (Fig. 2). Observed differences in variation within each age cohort may reflect genetic or environmental effects. Information regarding the husbandry (including culling and selection) of each age cohort in each sample group is incomplete; therefore, we cannot assume they faced the same environments during their life history. Even though the 2007 and 2009 Moreton Bay oysters were from the same breeding programme, information regarding the genetic uniformity of each group was not available. It is possible that different groups of brood stock are used in the mass selection programme over time or different lines may have been supplied to the oyster farmer.

This study on $S$. glomerata was useful for illustrating the heterogeneity of telomere dynamics that can be observed within a given species sampled from their natural setting. Telomere length of S. glomerata was observed to decrease with age only in young oysters sampled in this research project and then appeared to remain constant up to 4 years of age. Telomere length varied amongst tissue types and between similar-aged individuals in different locations. The relationship between telomere length and age was weak with individuals of identical age varying significantly in their telomere length. Telomere length and attrition rates also varied in different regions and were probably affected by genetic background and environmental effects.
The Roche TeloTTAGG kit, with its grid box method to determine signal volumes at given molecular weights, allowed acceptable estimates of telomere lengths to be made in this study. More precise estimates of telomere length may have been obtained if a pixel-based analysis method had been implemented such as that suggested by Haussmann and Mauck (2008). The box grid method lacks sensitivity because signal volumes are averaged over a range of molecular weights within each box, and measurement error is consequently greater, especially at high molecular weights.

Overall, we conclude telomere length is unsuitable as a biomarker of chronological age in oysters. These results support the claims by other researchers Horn et al. (2010), Monaghan (2010) and Dunshea et al. (2011) that telomere length has limited utility as an indicator of individual age. Further research, with greater sample sizes and age range, may tighten the relationship between telomere length and age in oysters; however, telomere length may prove to be more useful as a molecular indicator of physiological age than cronological age (Epel et al. 2004; Kotrschal et al. 2007; Salomons et al. 2009). For instance, it would be worthwhile assessing whether telomere length could be an indicator of stress and predict future mortality or whether the selection of individuals with long telomeres is useful in a breeding programme.

Acknowledgments We would like to thank Jane Clout and Anthony Sciacca for supply of the oysters, Vivek Mitter and Raewyn Street for technical assistance during the project and David Mayer for help with the statistical analyses. Also, we thank the project steering committee members for their support and advice; Melissa Brown, Damien Broderick, Phillip Gaffney, John Russell and Brian Patterson. Comments on the manuscript from Warwick Nash were appreciated. This project was co-funded by the Fisheries Research and Development Corporation (project number 2007/033).

\section{References}

Blackburn EH (1991) Structure and function of telomeres. Nature 350:569-573

Campana SE (2001) Accuracy, precision and quality control in age determination, including a review of the use and abuse of age validation methods. J Fish Biol 59:197-242

Cross I, Díaz E, Sánchez I, Rebordinos L (2005) Molecular and cytogenetic characterization of Crassostrea angulata chromosomes. Aquaculture 247:135-144

David E, Tanguy A, Pichavant K, Moraga D (2005) Response of the Pacific oyster Crassostrea gigas to hypoxia exposure under experimental conditions. FEBS J 272:5635-5652

Dinamani P (1974) Reproductive cycle and gonadal changes in the New Zealand rock oyster Crassostrea glomerata. N Z J Mar Freshw Res 8:39-65

Dove MC, O'Connor WA (2009) Commercial assessment of growth and mortality of fifth-generation Sydney rock oysters Saccostrea glomerata (Gould, 1850) selectively bred for faster growth. Aquac Res 40:1439-1450 
Dunshea G, Duffield D, Gales N, Hindell M, Wells RS, Jarman SN (2011) Telomeres as age markers in vertebrate molecular ecology. Mol Ecol Res 11:225-235

Epel ES, Blackburn EH, Lin J, Dhabhar FS, Adler NE, Jason DM, Cawthon RM (2004) Accelerated Telomere Shortening in Response to Life Stress. Proc Natl Acad Sci USA 101:17312-17315

Estabrooks SL (1999) The telomeres of the bay scallop, Argopecten irradians (Lamarck). J Shellfish Res 18:401-404

Estabrooks SL (2007) The possible role of telomeres in the short life span of the bay scallop, Argopecten irradians irradians (Lamarck 1819). J Shellfish Res 26:307-313

Francis N, Gregg T, Owen R, Ebert T, Bodnar A (2006) Lack of ageassociated telomere shortening in long- and short-lived species of sea urchins. FEBS Lett 580:4713-4717

Goewert AE, Surge D (2008) Seasonality and growth patterns using isotope sclerochronology in shells of the Pliocene scallop Chesapecten madisonius. Geo-Mar Lett 28:327-338

Greider C, Blackburn E (1985) Identification of a specific telomere terminal transferase activity in Tetrahymena extracts. Cell 43:405-413

Greider C, Blackburn E (1989) A telomeric sequence in the RNA of Tetrahymena telomerase required for telomere repeat synthesis. Nature 337:331-337

Guo XM, Allen SK (1997) Fluorescence in situ hybridization of vertebrate telomere sequence to chromosome ends of the Pacific oyster, Crassostrea gigas Thunberg. J Shellfish Res 16:87-89

Gurney LJ, Mundy C, Porteus MC (2005) Determining age and growth of abalone using stable oxygen isotopes: a tool for fisheries management. Fish Res 72:353-360

Hartmann N, Reichwald K, Lechel A, Graf M, Kirschner J, Dorn A, Terzibasi E, Wellner J, Platzer M, Rudolph KL, Cellerino A, Englert C (2009) Telomeres shorten while Tert expression increases during ageing of the short-lived fish Nothobranchius furzeri. Mech Ageing Dev 130:290-296

Hatakeyama H, Nakamura K-I, Izumiyama-Shimomura N, Ishii A, Tsuchida S, Takubo K, Ishikawa N (2008) The teleost Oryzias latipes shows telomere shortening with age despite considerable telomerase activity throughout life. Mech Ageing Dev 129:550-557

Haussmann MF, Mauck RA (2008) New strategies for telomere-based age estimation. Mol Ecol Resour 8:264-274

Haussmann MF, Vleck CM (2002) Telomere length provides a new technique for aging animals. Oecologia 130:325-328

Haussmann MF, Vleck CM, Nisbet ICT (2003) Calibrating the telomere clock in common terns, Sterna hirundo. Exper Gerontol 38:787-789

Horn T, Robertson BC, Gemmell NJ (2010) The use of telomere length in ecology and evolutionary biology. Heredity 105:497-506

Ivanina AV, Sokolova IM, Sukhotin AA (2008) Oxidative stress and expression of chaperones in aging mollusks. Comp Biochem Physiol B Biochem Mol Biol 150:53-61

Jennings BJ, Ozanne SE, Hales CN (2000) Nutrition, oxidative damage, telomere shortening, and cellular senescence: individual or connected agents of aging? Mol Genet Metab 71:32-42

Keller N, Del Piero D, Longinelli A (2002) Isotopic composition, growth rates and biological behaviour of Chamelea gallina and Callista chione from the Gulf of Trieste (Italy). Mar Biol 140:9-15

Kim NW, Piatyszek MA, Prowse KR, Harley CB, West MD, Ho PLC, Coviello GM, Wright WE, Weinrich SL, Shay JW (1994) Specific association of human telomerase activity with immortal cells and cancer. Science 266:2011-2015
Klapper W, Heidorn K, Kühne K, Parwaresch R, Guido K (1998a) Telomerase activity in 'immortal' fish. FEBS Lett 434:409-412

Klapper W, Kühne K, Singh KK, Heidorn K, Parwaresch R, Krupp G (1998b) Longevity of lobsters is linked to ubiquitous telomerase expression. FEBS Lett 439:143-146

Kotrschal A, Ilmonen P, Penn DJ (2007) Stress impacts telomere dynamics. Biol Lett 3:128-130

McShane PE, Smith MG, Beinssen KHH (1988) Growth and morphometry in abalone (Haliotis rubra Leach) from Victoria. Mar Freshw Res 39:161-166

Monaghan P (2010) Telomeres and life histories: the long and the short of it. Ann N Y Acad Sci 1206:130-142

Nakagawa S, Gemmell NJ, Burke T (2004) Measuring vertebrate telomeres: applications and limitations. Mol Ecol 13:2523-2533

Naylor JR, Manighetti BM, Neil HL, Kim SW (2007) Validated estimation of growth and age in the New Zealand abalone Haliotis iris using stable oxygen isotopes. Mar Freshw Res $58: 354-362$

Nell J (2001) The history of oyster farming in Australia. Mar Fish Rev 63:14-25

O'Connor W, Dove M (2009) The changing face of oyster culture in New South Wales, Australia. J Shellfish Res 28:803-811

Ojimi M, Hidaka M (2010) Comparison of telomere length among different life cycle stages of the jellyfish Cassiopea andromeda. Mar Biol 157:2279-2287

Owen R, Sarkis S, Bodnar A (2007) Developmental pattern of telomerase expression in the sand scallop, Euvola ziczac. Invertebr Biol 126:40-45

Passos JF, Saretzki G, von Zglinicki T (2007) DNA damage in telomeres and mitochondria during cellular senescence: is there a connection? Nucleic Acids Res 35:7505-7513

Payne R, Murray D, Harding S, DB B, Soutar D (2009) GenStat for Windows (12th Edition) Introduction. VSN International, Hemel Hempstead

Philipp EER, Abele D (2010) Masters of longevity: lessons from long-lived bivalves-a mini-review. Gerontology 56:55-65

Plohl M, Prats E, Martinez-Lage A, Gonzalez-Tizon A, Mendez J, Cornudella L (2002) Telomeric localization of the vertebratetype hexamer repeat, (TTAGGG)(n), in the wedgeshell clam Donax trunculus and other marine invertebrate genomes. J Biol Chem 277:19839-19846

Sakai M, Okumura SI, Yamamori K (2005) Telomere analysis of Pacific abalone Haliotis discus hannai chromosomes by fluorescence in situ hybridization. J Shellfish Res 24:1149-1151

Salomons HM, Mulder GA, van de Zande L, Haussmann MF, Linskens MHK, Verhulst S (2009) Telomere shortening and survival in free-living corvids. Proce R Soc B Biol Sci 276:3157-3165

Sambrook J, Russell DW (2001) Molecular cloning: a laboratory manual. Cold Spring Harbor Laboratory Press, Cold Spring Harbor

Shepherd S, Al-Wahaibi D, Al-Azri A (1995) Shell growth checks and growth of the Omani abalone Haliotis mariae. Mar Freshw Res 46:575-582

Siddeek M, Johnson D (1997) Growth parameter estimates for Omani abalone (Haliotis mariae, Wood 1828) using length-frequency data. Fish Res 31:169-188

Szostak J, Blackburn E (1982) Cloning yeast telomeres on linear plasmid vectors. Cell 29:245-255

Tarr R (1995) Growth and movement of the South African abalone Haliotis midae: a reassessment. Mar Freshw Res 46:583-590

Tsuji A, Ishiko A, Takasaki T, Ikeda N (2002) Estimating age of humans based on telomere shortening. Forensic Sci Int 126:197-199 
Vleck CM, Haussmann MF, Vleck D (2003) The natural history of telomeres: tools for aging animals and exploring the aging process. Exp Gerontol 38:791-795

von Zglinicki T (2002) Oxidative stress shortens telomeres. Trends Biochem Sci 27:339-344

von Zglinicki T, Martin-Ruiz CM (2005) Telomeres as biomarkers for ageing and age-related diseases. Curr Mol Med 5:197-203
Watson J (1972) Origin of concatemeric T7 DNA. Nat New Biol 239:197-201

Ying TC (2005) Evaluation of telomere length as an age-marker in marine species. Master of Philosophy, Hong Kong 